\title{
On Justifications and Excuses
}

\section{B.J.C. Madison}

(Forthcoming in Synthese)

Draft Version - Do Not Cite Without Approval

\section{Introduction:}

The New Evil Demon problem has been hotly debated since the case was introduced in the early 1980's (e.g. Lehrer and Cohen 1983; Cohen 1984), and there seems to be recent increased interest in the topic. In a forthcoming collection of papers on the New Evil Demon problem (Dutant and Dorsch, forthcoming), at least two of the papers, both by prominent epistemologists, attempt to resist the problem by appealing to the distinction between justification and excuses. My primary aim here is to critically evaluate this use of the excuse maneuver as a response to the New Evil Demon problem ${ }^{1}$.

Their response attempts to give us reason to reject the idea that victims of the New Evil Demon have justification for believing as they do. I shall argue that this approach is ultimately unsuccessful, however much of value can be learned from these attempts. In particular, progress in the debate can be made by following those who advance the excuse maneuver and make explicit the connection between

\footnotetext{
${ }^{1}$ Thanks to an anonymous referee for emphasizing that the excuse manoeuvre is not new to the Dutant and Dorsch volume. For example, Littlejohn (2009), section III.4 provides an in-depth examination of ways in which a subject's beliefs and actions may be blameless, justified, be exempt from responsibility, or excusable. Littlejohn's (2009) work in epistemology, in turn, appeals to similar distinctions drawn by others in epistemology, ethics, and law. My aim here, however, is to discuss the most recent presentations of the excuse manoeuvre as a response to the New Evil Demon problem, and the arguments given for it.
} 
epistemic justification and epistemic norms. By doing so, the questions being debated are clarified, as is the methodology being used to attempt to answer them.

\section{The New Evil Demon Case and Some Attempts to Resist It}

The New Evil Demon problem, in its most basic form, arises in the following way: consider a case where a subject is radically deceived about the external world, in ways completely undetectable by her. Compare this epistemically bad case with a corresponding good one - that is, consider a case of a subject who enjoys veridical experiences that are subjectively indistinguishable from her radically deceived counterpart, with the result that the beliefs she bases on these experiences are true. Although one subject has largely true, reliably produced beliefs, whereas her counterpart has false, unreliably produced beliefs, we are invited to register the evaluative judgment that the beliefs of the two subjects are equally justified. While they will of course differ in knowledge, since much of what the deceived subject believes is false, the two subjects are equally reasonable in believing as they do, and their beliefs are also equally reasonable ${ }^{2}$.

\footnotetext{
${ }^{2}$ Thanks to an anonymous referee who rightly pointed out that in analyzing New Evil Demon cases, people often conflate two evaluations, which must be kept distinct: the justification a person might have in holding a belief, and the justification a belief itself might enjoy. That is, a distinction is drawn between personal and doxastic justification. Relying on this distinction as a response to the New Evil Demon argument, some have argued that while the subjects may be justified in the New Evil Demon case, their beliefs are not. Advocates of this approach include Bach (1985); Engel (1992); Littlejohn (2009). The distinction itself between personal and doxastic justification can be traced back to at least Lowy (1978). As I am presenting the crucial intuition here, it is about both the subjects and their beliefs in New Evil Demon scenarios: both the subjects and their beliefs are as equally well justified as their normal world counterparts.

Intuitive considerations aside, the plausibility of a response based on distinguishing personal from doxastic justification will turn on the coherence of a person being justified in believing that $\mathrm{P}$ while her belief that P is itself unjustified. According to Kvanvig and Menzel (1990), for example, a person's being justified in believing that $\mathrm{P}$, entails that his belief that $\mathrm{P}$ is justified - one cannot have the former without the latter.
} 
If this judgment is correct, then it refutes many different kinds of epistemic externalism. Take for example traditional forms of process reliabilism (e.g. Goldman $1979 ; 1986)$, and also forms of virtue epistemology, for which reliability plays a key role (e.g. Sosa 2007). According to such views, it is at least a necessary condition of a belief being justified that it is reliably produced. But if it is correct that the radically deceived twin has no more, and no fewer justified beliefs than her normal world counterpart, and that her beliefs are no more and no less justified, then it is false that justification requires reliability.

Consider also that if the central lesson of New Evil Demon cases is correct, then it also poses a counterexample to epistemological disjunctivism, a more recent theory that holds that the rational support a subject has for her beliefs differs between good and bad cases (e.g. Pritchard 2012).

In addition, if arguments arising from New Evil Demon considerations are sound, they will undermine the newly emerging factive-turn in epistemology, one that posits factive norms of belief, which can in turn generalize to factive norms of assertion. Factive norms are ones that are truth entailing, such as the following candidates that have been proposed: assert (or perhaps believe) that $\mathrm{P}$ only if one knows that $\mathrm{P}$ (e.g. Williamson 2000); a belief that $\mathrm{P}$ is justified IFF one knows that $\mathrm{P}$ (Sutton 2007); believe that $\mathrm{P}$ only if it is true that P (Littlejohn 2012); assert that $\mathrm{P}$ only if it is true that P (Weiner 2005), and so on. If it is correct that in a case of radical deception a false belief can still be properly or justifiably held, and that the assertion of falsehoods can still be warranted, then it is false that truth is a necessary condition of justification or warranted assertion. Given the significance of the possible wide-reaching consequences of the New Evil Demon problem, it is important to assess some recent attempts to resist it. 
A recent family of strategies has emerged in responding to New Evil Demon cases. Opponents of New Evil Demon cases have held that subjects in the deception cases are not justified, and they then attempt to explain away contrary intuitions that justification is present. One way of providing such an error theory is to identify a positive epistemic standing in the bad case that falls short of epistemic justification, but could plausibly be confused for it (cf. Kegan Shaw (forthcoming) on some possible confusion candidates).

For example, Duncan Pritchard (2012) has offered what we can call The Mere Blamelessness Account. In the course of defending epistemological disjunctivism, a position which entails that in the bad case either the subject lacks justification, or else they have less of it than in a good case, Pritchard argues that while New Evil Demon victims beliefs' lack justification, they are nevertheless blameless in believing as they do. I have attacked this approach by providing cases that purport to show that blamelessness is insufficient to account for the positive epistemic standing in the bad case, arguing that the initial judgment that the subjects have justification to believe as they do should be retained (Madison, 2014).

A representative case against The Mere Blamelessness Account is as follows: compare three subjects, each of whom believes that $\mathrm{P}$. The first believes that $\mathrm{P}$ because he sees that $\mathrm{P}$ (as seeing-that is a factive relation, it is true that $\mathrm{P}$ ). His recently envatted counterpart also believes that $\mathrm{P}$, however he believes that $\mathrm{P}$ because he seems to see that $\mathrm{P}$, although he is hallucinating. Compare these two subjects with the third: this subject also believes the same proposition, but does so merely because he is brainwashed. The three subjects all believe the same proposition, and they are all blameless in believing as they do: the first two believe what their evidence supports; the third, in turn, cannot be faulted for being the victim of brainwashing. 
But while all are blameless in believing as they do, it seems that the first two subjects are in a better justificatory position than the third subject, who merely believes as he does because he is brainwashed. It also seems that the first two subjects are equally well justified in their beliefs.

If this reasoning is sound, then mere blamelessness is insufficient to account for the positive epistemic status of the beliefs in cases of subjects and their evil demon-deceived counterparts (see Madison 2014 for an extended argument against The Mere Blamelessness Account). I have tried to show that mere blamelessness is insufficient to account for the positive epistemic standing in such cases. But for all I have argued, it could be that more nuanced conceptions are available of what goes well, epistemically, in New Evil Demon cases, that nevertheless fall short of justification.

What we can call The Excuses Account represents an advance over The Mere Blamelessness Account. Clayton Littlejohn (forthcoming) and Timothy Williamson (forthcoming) urge us to distinguish among justifications and normative statuses that fall short of it. While justification might entail blamelessness, there could be other ways that one might be blameless that fall short of justification. For example, one might be blameless because of an exemption: if an infant releases a parking brake and the car rolls over someone and kills them, then while tragic, the infant is blameless. This is because they are exempt from responsibility, as they are not yet moral agents. Moral praise and blame do not apply to them.

Another way that one might be blameless, but which also falls short of justification, is when one has a good excuse. One has a good excuse when, roughly, although what one did is wrong and is therefore properly criticizable, there is a 
consideration that lessens the degree of blame appropriate, perhaps even to the point of blamelessness. For example, a professor might have a course policy that students must attend class. If a student misses class, then they violate the rule, and so their action is properly criticizable. However, a student might also have a medical certificate, which has the function of excusing them from blame for not attending class. The student's missing class is still wrong, however, as it contravenes the course policy. The student would not need an excuse unless they had done something that was wrong, and so not justified. Having an excuse casts what they did in a new light, so the absence is not a wrong for which the student should be blamed ${ }^{3}$.

Since being excusable is a positive standing, more than mere blamelessness, but distinct from justification, perhaps New Evil Demon victims lack justification for their beliefs, though the beliefs are excusable. If this is correct, it would prove to be a promising way to resist New Evil Demon cases and thereby defend the externalist epistemologies they threaten to undermine.

\section{A Recent Model of Justifications and Excuses}

Timothy Williamson (forthcoming) has recently proposed a novel account of how to understand the distinction between justification and excuses. With a general account in hand, he then applies this model to the New Evil Demon problem in an attempt to explain away intuitions that the deceived subjects have justification for their beliefs. As Williamson sees it, epistemic justification comes from meeting epistemic norms, whereas excuses arise derivatively for those who violate epistemic norms, but have the intellectual character and dispositions of those who meet the

\footnotetext{
${ }^{3}$ Thank you to an anonymous referee for impressing upon me the need to be explicit about this point.
} 
norm. By way of illustration of how the model is meant to work, it is easiest to begin with examples outside the epistemic case.

Consider a law which forbids jaywalking. One complies with the law if and only if one does not jaywalk, and one's street crossing is justified, and legal, insofar as one does not cross the road outside of crosswalks, etc. If one jaywalks, for whatever reason, one breaks the law, and one does so without justification. On Williamson's view, from the primary norm which defines justification, other norms can be derived, which turn in generate excuses, such as the following "DN: an agent should be the kind of person who is disposed to comply with N" (Williamson, forthcoming, p. 6). DN might be satisfied in the following way: while one might be the kind of person who is strongly disposed to obey the law and not jaywalk, one might be unwillingly and forcefully dragged across the street. Williamson's account would imply that while this roadcrossing was not justified, as it was illegal, it is nevertheless excusable. One's action is blameless, and it is blameless because it is excusable.

On Williamson's account, excuses can be generated in other ways, such as the following: "ODN: an agent should do what a person who is disposed to comply with $\mathrm{N}$ would do in the relevant circumstances" (Williamson (forthcoming, p. 6). To see how this is meant to work, suppose that an anarchist unlawfully paints a "crosswalk" on the street. This is therefore not a genuine crosswalk, but it is subjectively indistinguishable from the genuine article. Suppose also that one sees the ersatz crosswalk, and crosses the street accordingly. While one is breaking the law by jaywalking, and so one's action is not justified, one is doing what a person who is disposed to comply the anti-jaywalking would do in the circumstances. It plainly 
looks like a crosswalk, afterall, and so one's using it to cross the street is completely excusable.

Transposing this model of justifications and excuses to epistemology, one could adopt a factive norm of belief, such as a knowledge norm, which holds that one should only believe that $\mathrm{P}$ if one knows that $\mathrm{P}$. Call this norm $\mathrm{N}$ : a subject's belief is justified if $\mathrm{N}$ is met. If a subject fails to know, for whatever reason, then their belief lacks justification. But then what of the judgment that something is going well for the deceived subject's beliefs in the New Evil Demon cases where they fail to have knowledge, if their beliefs are not justified? On Williamson's view, even in the demon world an agent can still be the kind of person who is disposed to comply with $\mathrm{N}$; in addition, as the subject has a knowing counterpart in the non-demon world, the deceived subject is still doing what a person who is disposed to comply with $\mathrm{N}$ would do in the relevant circumstances. So while a subject might lack justification due to the meddlings of the demon, Williamson's account delivers the result that the beliefs of such subjects are excusable, since they still retain the intellectual character and dispositions of those who meet the primary norm.

The distinction drawn between justification and excuses might be good as far as it goes, and here I will accept it for the sake of argument. By offering a more nuanced account of different ways of being blameless, it does represent a significant advance in the debate over responses to the New Evil Demon case that submit that demon-world subjects hold merely blameless belief. But the appeal to excuses in these cases proceeds from the claim that systematically deceived subjects only deserve to be credited with excuses, since they fall short of justification for believing as they do. They lack justification, it is held, because they do not meet the primary 
norm of belief. But a key question remains: why think that demon world subjects fail to comply with primary epistemic norms? ${ }^{4}$

The internalist supporter of the New Evil Demon case can, and I suggest should, agree with those like Williamson and Littlejohn that a belief is justified IFF it meets the key normative standard for the epistemic assessment of beliefs (Williamson, p.1). But what is that standard, and how do we discover its nature? How do we tell what counts as an instance of complying with or violating the standard? To answer these questions we need to turn to issues surrounding the nature of norms of belief.

\section{On Norms of Belief}

I will follow Williamson and take norms to be anything that yields some sort of 'ought' or 'should' (Williamson, forthcoming, p.4). So epistemic norms specify what people should or ought to believe, in given circumstances. Williamson claims to start with putative "truth-related norms": e.g. "that one's belief should be true; that one's beliefs should constitute knowledge; that one's beliefs should be probable on one's evidence; that one's beliefs should be consistent." (p.12). While these of course are not unreasonable suggestions, one cannot help but wonder: why these norms, and not others? How would we know which are correct? Other important questions arise too, such as: is a belief justified if it complies with all, any, some, or most of these

\footnotetext{
${ }^{4}$ An anonymous referee suggested looking beyond the discussion of excuses for arguments that the primary epistemic norm is not met. Williamson (2000) and Littlejohn (2012) do offer independent arguments for the knowledge norm and the truth norm of belief, respectively. But rather than evaluating those arguments directly here, I shall be making a general methodological proposal about the basis upon we should identify epistemic norms, as well as make judgements about whether the norms have been met. My suggestion will be that doing so makes the appeal to excuses in New Evil Demon cases unmotivated.
} 
norms? If there is more than one norm of belief, might some be primary or more fundamental?

In deciding whether given beliefs are justified, Williamson provides a couple cases, and then says of the believer in each, things like the following: "But she does not comply with the original norm $\mathrm{J}$, if that norm is plausibly sufficient for justification in any serious sense. Although her belief $[\ldots]$ does at least satisfy the minimal norm of consistency, that norm is too weak to be a plausible standard for justification." (p.17) What is the basis of judgments about what is a plausible standard of justified belief? In particular, why think that the relevant norm is violated in these cases, and in the New Evil Demon cases, and complied with in good cases? In order to adequately answer these questions we need to be explicit about the methodology used to identify epistemic norms.

While talk of the norms of belief is still an emerging discussion, perhaps some insights can be borrowed from a well-established debate about epistemic norms, namely the debate about the epistemic norms governing the speech-act of assertion. Jennifer Lackey (2007) is one philosopher who is explicit about the methodology in play in the norms of assertion debate: in order to identify norms of assertion, we need to consider actual and possible cases of assertion, and then look for the conditions under which it is appropriate to criticize, and by contrast, praise particular assertions. Criticism reveals what we judge to be (epistemically) wrong with an assertion; praise, on the other hand, reveals that no norm of assertion is violated ${ }^{5}$. Likewise, my

\footnotetext{
${ }^{5}$ An anonymous referee questioned whether the turn to Lackey is particularly helpful here. They suggested that, arguably, she is guilty of conflating two kinds of assessment: roughly, the assessment of the person, vs. the assessment of her beliefs / assertions. See note 2 above on the distinction between personal and doxastic justification.

Regardless of whether or not Lackey herself runs these assessments together in the work cited, we can keep them apart. While it might ultimately prove to be a mistake that the criticism of assertions reveals anything about norms and their violation, the assumption is ubiquitous in the norms of assertion
} 
suggestion is that we ask of various beliefs held by subjects, which are properly criticizable, and which are to be praised? This will reveal what we take to be epistemically wrong, as well as when beliefs meet the relevant norms.

If we reflect on the false beliefs of evil demon victims, it seems that there is nothing to criticize. The subjects, like their non-deceived counterparts, proportion their beliefs with how things appear to them to be. If it seems to a subject that they have hands, for example, and they are not presented with any defeaters, then they believe that they have hands. In such circumstances, such beliefs should be praised, rather than criticized. If in such circumstances, subjects had instead disbelieved that they had hands, or suspended judgment on the matter, then these attitudes would surely be deserving of criticism. So why then are an increasing number of philosophers critical of the beliefs held in New Evil Demon cases?

When evaluating the beliefs of a New Evil Demon victim, the critics' core idea seems to be that false beliefs are defective, and the defective is bad $^{6}$. For example, Williamson writes, "As most epistemologists accept, a false belief is somehow defective. In particular, the brain in the vat's false beliefs are defective." (Williamson, p. 24) The internalist supporter of the New Evil Demon case can accept that false beliefs are somehow defective - perhaps belief in some sense 'aims at truth', for example. But if false beliefs are epistemically bad, that does not in itself entail wrongness. So we must reject characterizations like this:

\footnotetext{
debate. For example, in discussing norms of assertion in an encyclopedia overview, Pagin (2016) notes: "A large part of the intuitions that serve to support one or the other norm theory relies on raw intuitions about what one should or shouldn't assert in some situation, or what is proper or improper to assert there." So too here, the suggestion is to apply that methodology, commonplace in the norms of assertion debate, to this seemingly parallel debate about the norms governing belief.

${ }^{6}$ While there might be other arguments for norm violation in such cases, other than from premises involving the badness of false belief, this style of argument is extremely common, and Williamson endorses it in the discussion in question. Accordingly, it is worth noting that this particular argument is invalid (granting that it might not be the only argument available). I thank an anonymous referee for raising this issue.
} 
“There are important differences between [Marcia] Baron's example [in which someone does nothing wrong at all] and the BIV [Brain-in-a-Vat]. For one thing, by stipulation, the BIV does something wrong [original emphasis]. He forms systematically false beliefs.” (Boult, 2016, p. 8)

It is important that we do not slip into stipulating that something wrong has been done - that is a further open evaluative question to be answered. Instead, in setting up New Evil Demon cases, we simply stipulate systematic falsity. We must distinguish wrongness vs. badness, just as we must distinguish rightness from goodness. Holding false beliefs might be bad, without it thereby being wrong. A false belief might not be deserving criticism, but instead perhaps something like regret. To see this, consider that in general a state of affairs might be bad, without the action that brought it about being wrong. In that case, the action does not deserve criticism, but instead perhaps regret. For example, suppose that an invisible child is playing in the street, and someone runs over the child in their car, killing the child instantly. I submit that the action of running over an invisible child would result in a bad state of affairs, but the action would not be wrong, as such. It would be inappropriate to criticize the action, although it is indeed regrettable that an innocent child died. Badness does not entail wrongness, and the justification of actions and beliefs is matter of avoiding the latter.

But one might object: if regret is appropriate, does that not entail responsibility? And if one is responsible for bringing about a bad state of affairs, does that not entail that one's action is properly deserving of criticism after all? While regret is consistent with responsibility and being properly deserving of criticism, it does not entail it. For example, if I regret that you missed a brilliant play, it does not entail that it is my fault that you missed the play. I might also express my 
regret at your death, but that does not entail that I am responsible for your death. Often regret expresses sadness that something happened, without admitting guilt or wrongdoing.

My proposal is that we apply the methodology for adjudicating the norms of assertion debate to the question of the norms of belief operative in New Evil Demon cases. First we present a New Evil Demon case, and then we register the evaluative judgment that there is sameness of justification between normal world subjects and their demon-world counterparts. It is important to note that these are purely evaluative judgments about the presence of justification in various hypothetical circumstances, not a conclusion reasoned to from various premises (cf. Madison, 2014, p.67). We must now go on to further note that there is nothing wrong or critizable in the subjects so believing, allowing that such beliefs might still be defective because false, and therefore bad in some sense. But since there is nothing to criticize, we have reason to think that, whatever the norms of belief might be, the relevant norm has been met, and so the subject's beliefs are justified.

Holding that the demon world subjects are justified is one thing, but uncovering exactly what the norms of belief must be is a crucial, but independent further question. The thesis that justification is present in the demon world can be supported by the fact that no more or no fewer beliefs are properly subject to criticism than the beliefs of these subjects' normal world counterparts. From the bolstered judgment that justification is present, we can now try to uncover what those norms must be. There are a number of possible suggestions to assess, but what they all have in common is that they must meet the following constraint: it is possible that these norms can be met in a demon world. Possible candidate norms suggest themselves: if one has an experience that represents that $\mathrm{P}$, believe that $\mathrm{P}$ (in the absence of 
defeaters); if it seems to one that $\mathrm{P}$, believe that $\mathrm{P}$ (in the absence of defeaters), etc. To be sure, whatever the norm(s) of belief is, it is met in the New Evil Demon case.

So rather than demon world victims having merely excusable beliefs, we have reason to think that they have justified beliefs, since they are believing as they should, or as they ought, since their beliefs are praiseworthy, rather than the proper objects of criticism. A belief is justified IFF it meets the norm of belief, and it is judgments about the appropriateness of praise and criticism that provide evidence for what the norms are, and whether or not they are met. Of course, the support of any intuition is defeasible. But hopefully enough has been done to show that a firm judgment can be elicited about whether justification is present in New Evil Demon scenarios by specifically considering what, if anything, is properly criticizable in such cases. Whether such support can be ultimately defeated by further considerations is another question. It is to one such attempt to defeat that judgment that we now turn.

\section{Contrast Arguments}

Littlejohn (forthcoming) criticizes the above methodological approach by arguing that it is an example of a fallacious form of argument he calls a "Contrast Argument”. As Littlejohn sees it, defenders of the New Evil Demon tend to embrace the following argumentative strategy: a New Evil Demon victim's beliefs have something positive going for them; this positive status must either be justification or blamelessness; their beliefs are not merely blameless; therefore they are justified (Littlejohn, forthcoming, pp.7-8). Littlejohn rightly points out that this is a bad argument, since it assumes the false dichotomy that positive epistemic standing in 
these cases must only be either justification or mere blamelessness, and this ignores other kinds of blamelessness, such as exemptions, excuses, etc.

In response, I think that both indirect and direct strategies are available to those who hold that New Evil Demon victims have justified beliefs. By an indirect strategy, I mean something purely defensive. In this case one does not offer positive independent support for the judgment that victims of the new Evil Demon have justified beliefs. Instead, one begins with the judgment that justification is present -perhaps that is known immediately, or intuitively. One then proceeds to merely defend the claim by arguing against competing explanations of the phenomena. A direct response, on the other hand, provides positive independent premises, and reasons from them to the conclusion that justification is present in New Evil Demon cases. The difference in approach is between the New Evil Demon judgment being a starting point which one then defends, or a conclusion one arrives at on the basis of argument.

With this distinction in hand, we can first think of so-called Contrast Arguments as defending judgments about New Evil Demon cases, not as establishing them on the basis of reasoning. The defense proceeds by challenging alternative interpretations of the cases. In other words, suppose that I hold that New Evil Demon subjects beliefs' are justified, and you counter that they are merely X (merely blameless, excusable, etc). One can then respond by assuming for the sake of argument that the beliefs are justified or that they are merely X. One can then attempt to show that the beliefs in question are not merely $\mathrm{X}$, and therefore that they are justified. 
None of this indirect defense of course conclusively proves that the beliefs are justified - perhaps the beliefs will turn out to be best understood as enjoying another positive epistemic standing that was previously unconsidered. Still, offering such a defense will be enough to deflect alternative interpretations of the case, and so to leave the initial intuitive judgment of the presence of justification intact. It seems that there is nothing wrong with this form of argument in general, on pain of losing disjunctive syllogism and arguments by elimination more generally as legitimate forms of argument.

A more direct argument can also be advanced in response to Littlejohn's discussion of Contrast Arguments ${ }^{7}$. As we saw above, Littlejohn sees defenders of the New Evil Demon as fallaciously arguing as follows:

1) The New Evil Demon victims' beliefs are either justified or merely blameless;

2) Their beliefs are not merely blameless;

Therefore,

3) Their beliefs are justified.

As I noted above, this is a bad argument since premise 1 expresses a false dichotomy.

In response, in light of the distinction between justification and excuses, the defender of the New Evil Demon can add the missing disjunct, as follows:

$1^{*}$ ) The New Evil Demon victims' beliefs are either justified, or merely blameless, or merely excused.

$\left.2^{*}\right)$ Their beliefs are neither merely blameless nor are they merely excused.

Therefore,

\footnotetext{
${ }^{7}$ Thanks to an anonymous referee for suggesting these direct lines of argument.
} 
3) Their beliefs are justified.

Premise $2 *$ is a central claim that I defend in this paper. As I argued above, their beliefs are not merely excusable, as they are not properly criticizable - which is to say that they therefore meet the norm of belief. In agreement with Williamson and Littlejohn, I have been assuming that a belief's being justified is simply a matter of it meeting the norm of belief.

Tying these points together yields the following additional direct argument for the conclusion that New Evil Demon victims have justified beliefs:

$\left.1^{* *}\right)$ The beliefs of New Evil Demon victims are either merely blameless or merely excusable or are not properly criticizable;

$\left.2^{* *}\right)$ Their beliefs are neither merely blameless nor are they merely excusable;

Therefore,

3**) Their beliefs are not properly critizable;

$4 * *)$ Beliefs that are not properly critizable are justified;

Therefore,

$\left.5^{* *}\right)$ Their beliefs are justified.

These latter two Contrast Arguments do not rely on the false dichotomy that Littlejohn rightly criticizes. The second of the two arguments also incorporates as a premise a key insight from Williamson and Littlejohn, namely that epistemic justification is a matter of meeting epistemic norms. I have also defended the remaining premises above; there is nothing to criticize about New Evil Demon 
victims beliefs simply because they are false. These premises together jointly entail the conclusion that beliefs of New Evil Demon victims are epistemically justified.

Littlejohn (forthcoming) also objects that advocates of Contrast Arguments tend to direct their focus off target: "If someone offers a justification, you'd expect considerations that would purport to show that the subject had sufficient reason for her actions or attitudes would be front and center. What we find instead is a focus on things like praiseworthiness, character, responsibility, whether the subject could feel guilt, and how reasonable or rational the subject was. [...] What's not clear from these passages is what role considerations about fault, blame, and responsibility have to do with grounds, reasons, or evidence.” (pp.8-9)

Littlejohn is correct that the primary focus of advocates of Contrast Arguments should be on whether beliefs are justified, and that turns on the grounds, reasons, or evidence for which the beliefs are held. But as we saw in section 3 above, evidence that epistemic norms are met, and so which beliefs are justified, can be found by noting what is properly criticizable. We should primarily focus on whether the beliefs themselves are criticizable in any relevant sense. But praiseworthiness, character, responsibility, whether the subject could feel guilt, and how reasonable or rational the subject was, can offer some guide to the justifiedness of belief. If beliefs are justified, these positive features of the person are very often co-present, and so can be some indirect evidence that beliefs are justified. That is, if a subject is praiseworthy in how she holds a belief etc., we can ask: what best explains these related phenomena? Very often the best explanation shall be that the subject's beliefs themselves are justified. If the beliefs themselves are able to be properly criticized, on the other hand, this will reveal that the beliefs lack justification. 


\section{Conclusion: Cases-First Epistemology}

The New Evil Demon case is an important thought experiment to discover, clarify, and argue about the fundamental nature and value of epistemic justification. Some have contended that 'epistemic justification' is a quasi-technical term, and so it is difficult at best to elicit clear and reliable pre-theoretical judgments about it (e.g. Cohen 2016). A change of focus to epistemic norms can help address this concern: if a belief is justified IFF it meets the primary epistemic norm, and meeting epistemic norms is a matter of believing as one should, or ought, we are more easily able to make clear and firm pre-theoretical judgments about what people ought to believe in various circumstances. This is so in the epistemic case, just as in moral philosophy we are more easily able to make clear and firm pre-theoretical judgments about what people ought to do in various circumstances, rather than beginning by asking questions involving quasi-technical terms like "moral rightness". Helping guide all of these normative judgments is sensitivity to what is properly subject to criticism. While The Excuses Account ultimately does not give us sufficient reason to give up the judgment that New Evil Demon victims are justified in their beliefs, it does advance the debate by shifting our focus onto central questions surrounding the norms of belief.

And how do we discover and confirm epistemic norms? My view is that we must rely on evaluative judgments about cases. Some will scoff, insisting that this methodology is in some sense question-begging, or perhaps indecisive at best. Instead, it has been suggested that these questions must be answered by appeal to “substantive considerations" (Littlejohn, forthcoming, pp. 4; 14-15; 26). Given that we are asking such fundamental questions about what people should or ought to believe, what could such considerations be? Importantly, why might these other 
considerations have priority over evaluative judgments? In addition, it seems to be an evaluative judgment itself that "substantive considerations" are more probative than direct evaluative judgments about cases. Reliance on fundamental evaluative judgments, therefore, is inescapable ${ }^{8}$.

\footnotetext{
${ }^{8}$ Thanks to audiences at the Australasian Association of Philosophy Annual Conference in Melbourne, and the Normativity \& Rationality Seminar at King's College London. Thanks also to two anonymous referees for Synthese, Kegan Shaw, Clayton Littlejohn, Stephen Hetherington, and especially Rhiannon James for helpful discussion and written comments on earlier drafts of this paper.
} 


\section{Sources Cited}

Bach, Kent. (1985) “A Rationale for Reliabilism.” The Monist 68: 246-63.

Boult, Cameron. (2016) "Epistemic Normativity and the Justification-Excuse

Distinction”. Synthese. DOI 10.1007/s11229-016-1127-8.

Cohen, Stewart. (1984) 'Justification and Truth'. Philosophical Studies 46. 279295.

Cohen, Stewart. (2016) "Theorizing About the Epistemic". Inquiry. DOI:

10.1080/0020174X.2016.1208903.

Dutant, J. and Dorsch, F (ed.). (forthcoming) The New Evil Demon. Oxford University Press.

Engel, Mylan. (1992) “Personal and Doxastic Justification.” Philosophical Studies 67: 133-51.

Goldman, Alvin. (1979) 'What Is Justified Belief'. Justification and Knowledge. Ed. George Pappas. Dordrecht, Holland: D. Reidel: 1-23.

Goldman, Alvin. (1986) Epistemology and Cognition. Cambridge, Mass.: Harvard University Press.

Lehrer, Keith and Cohen, Stewart. (1983) "Justification, Truth, and Coherence". Synthese 55: 191-207.

Littlejohn, Clayton. (2009) “The Externalist's Demon” in Canadian Journal of Philosophy 39: 399-434.

Littlejohn, Clayton. (2012) Justification and the Truth-Connection. Cambridge: Cambridge University Press.

Littlejohn, Clayton. (Forthcoming) “A Plea for Epistemic Excuses" in Dutant and Dorsch.

Lackey, Jennifer. (2007) "Norms of Assertion”. Nous 41: 594-626.

Lowy, Catherine. (1978) “Gettier's Notion of Justification.” Mind 87.345: 105-108.

Kvanvig, Jonthan and Menzel, Christopher. (1990) "The Basic Notion of Justification." Philosophical Studies 59.3: 235-61. 
Madison, B.J.C. (2014) "Epistemological Disjunctivism and the New Evil Demon". Acta Analytica 29: 61-70.

Pagin, Peter. (2016) "Assertion", The Stanford Encyclopedia of Philosophy (Winter 2016 Edition), Edward N. Zalta (ed.), URL = $<$ https://plato.stanford.edu/archives/win2016/entries/assertion/>.

Pritchard, Duncan. (2012) Epistemological Disjunctivism. Oxford. Oxford University Press.

Shaw, Kegan. (Forthcoming) “A Better Disjunctivist Response to the 'New Evil Genius' Challenge”. Grazer Philosophische Studien.

Sosa, Ernest. (2007) A Virtue Epistemology: Apt Belief and Reflective Knowledge, Volume 1. Oxford: Oxford University Press.

Sutton, Jonathan. (2007) Without Justification. Cambridge, Mass.: The MIT Press. Weiner, Matthew. (2005) "Must We Know What We Say?" The Philosophical Review 114: 227-251.

Williamson, Timothy. (2000) Knowledge and Its Limits. Oxford: Oxford University Press.

Williamson, Timothy. (Forthcoming) “Justifications, Excuses, and Sceptical Scenarios" in Dutant and Dorsch. 